\title{
Sexual selection on chromosomal polymorphism in Drosophila subobscura
}

\author{
Mauro Santos, Rosa Tarrío, Carlos \\ Zapata and Gonzalo Alvarez*
}

\begin{abstract}
Departamento de Genética, Facultad de Biología, Universidad de Santiago de Compostela, Santiago de Compostela, Spain.
\end{abstract}

\begin{abstract}
Experiments were conducted to analyse the pattern of mating and to look for sexual selection differences among karyotypes of Drosophila subobscura. This was done by assaying the mating structure of large experimental populations of this species set up with different frequencies of $\boldsymbol{O}_{\mathrm{Sr}}$ and $\boldsymbol{O}_{3+4+7}$ chromosomal arrangements. From the experimental results, it is concluded that the mating pattern is at random and that the mating success of the male homokaryotypes $O_{\mathrm{ST}} / O_{\mathrm{ST}}$ and $\boldsymbol{O}_{3+4+7} / O_{3+4+7}$, relative to that of the heterokaryotype $\boldsymbol{O}_{\mathrm{ST}} / \boldsymbol{O}_{3+4+7}$, is frequencydependent favouring the rare male. These results are discussed in connection with the stable equilibrium attained in experimental population cages containing the $\boldsymbol{O}_{\mathrm{ST}}$ and $\boldsymbol{O}_{3+4+7}$ chromosomal arrangements.
\end{abstract}

\section{INTRODUCTION}

In his book Genetic Models of Sexual Selection, O'Donald (1980) provides a thorough discussion of the development of the theory of sexual selection. By sexual selection is understood the differential ability of genotypes of either sex to attract mates and there has been an ample controversy on the mechanisms by which this important selective component operates. With his usual flair Darwin (1871) put forward a theory which has been proved to be essentially correct and is at the present time an active research area.

In the earlier experiments on mating success carried out by Petit with Drosophila melanogaster and Ehrman with D. pseudoobcura (see Petit and Ehrman, 1969), an interesting phenomenon was brought to light: the existence of frequency-dependent selection favouring the minority males. This phenomenon, repeatedly reported in later experiments (the literature has been summarised by Petit and Ehrman, 1969; Ehrman and Parsons, 1976; Bryant et al., 1980; Spiess, 1982), has potentially important evolutionary implications. However, the mechanisms underlying the rare male mating advantage are not clear and several models have been developed (O'Donald, 1977, 1980; Spiess, 1982). Whatever the correct model, the important

\footnotetext{
* To whom reprint requests should be sent.
}

point is that the existence of a frequency-dependent selection favouring the rare male genotype can play a significant role in maintaining genetic variability (Anderson, 1969).

Investigations on polymorphisms in experimental populations have revealed a variety of selective forces which, as Prout $(1969,1971 a, b)$ has demonstrated, can be ideally measured by means of a detailed description of the different selection components and of the mating pattern. The concept of partitioning the action of natural selection into several fitness components has been an important one in stimulating well-designed experiments demonstrating the significance and relative importance of the various components of natural selection. Contrary to the traditional belief about the action of natural selection was the evidence that the adult male component, instead of viabilities of zygotes, played a decisive role in the genetic make-up of different Drosophila populations (Prout, 1971a, b; Bundgaard and Christiansen, 1972; Anderson et al., 1979; Brittnacher, 1981). In addition, there is also extensive evidence that sexual selection is an important component in the dynamics of polymorphisms (Anderson and Watanabe, 1974; Anderson and McGuire, 1978; Fontdevila and Méndez, 1979; Anderson and Brown, 1984). One point that deserves attention is that a clear distinction between mating success and pattern of mating was not always made in the 
experiments on mating behaviour. Mating success concerns frequency of mating whereas pattern of mating (random, consanguineous, assortative, etc) is choice of mate which is not directly related to sexual selection. Besides selection, mating pattern is an important determinant of the genotypic composition of the population and a clear distinction between both phenomena is necessary in order to avoid confusion in the description of the operation of selection (Alvarez et al., 1984; Santos et al., 1984).

Chromosomal inversion polymorphisms are common in natural populations of many Drosophila species and have been extensively utilised as a powerful tool for the analysis and measurement of selection in both experimental and natural populations. Large differences in adaptive values have been usually found and selection may operate on several phases of the life-cycle (Dobzhansky, 1970). Some of the selective forces acting on inversion polymorphisms have been identified and the observation that inversions affect various aspects of mating in Drosophila has been usual (Monclús and Prevosti, 1971; Anderson and Watanabe, 1974; Yu and Spiess, 1978; Anderson and Brown, 1984).Although the preservation of chromosomal variability in natural populations is undoubtedly due to balanced polymorphism, there is, however, some question about the type of selection responsible for the maintenance of this widespread variability. Three basic selective mechanisms may be important in explaining stable polymorphism: environmental heterogeneity, frequency-dependent selection favoring the rare genotype and heterosis. However, with regard to chromosomal variability it should be interesting to discover the level of genetic organisation of the gene arrangements since selection can operate on inversions at several different levels (Wasserman, 1968, 1972). If epistatic interactions among genes within the inversion are important, recombination between different supergenes of the same inversion would destroy the good supergenes and would generate frequency-dependent selection against the more common inversion homozygote. With regard to $D$. subobscura, species known to be very rich in chromosomal polymorphism(Krimbas and Loukas, 1980), it now seems clear that the gene arrangements found in natural populations are not subject to constant fitnesses and show seasonal changes which cannot be explained by genetic drift (Fontdevila et al., 1983). Several results from our laboratory (Zapata et al., 1986) demonstrate the existence of stable polymorphism for the $O_{\mathrm{ST}}$ and $\mathrm{O}_{3+4+7}$ chromosomal arrangements in experi- mental populations maintained in different environmental conditions. Our aim in the present work is to analyse the role of sexual selection in the maintenance of this chromosomal polymorphism. This will be done by assaying the mating structure of large experimental populations of $D$. subobscura set up with different frequencies of $O_{\mathrm{ST}}$ and $\mathrm{O}_{3+4+7}$ gene arrangements.

\section{MATERIALS AND METHODS}

\section{Laboratory strains}

The following two stocks of $D$. subobscura, kindly sent to us by D. Sperlich, were used to obtain the flies for the sexual selection experiments: (a) a stock homozygous for the recessive mutants curled ( $c u$, curled wings) and cherry (ch, bright red eye colour), both on the $O$ chromosome (Koske and Maynard Smith, 1954). The cu-ch strain is homokaryotypic for the $\mathrm{O}_{3+4}$ chromosome arrangement. (b) The balanced lethal $V a / B a$ strain for the chromosome $O$ (Sperlich et al., 1977). This stock carries the dominant visible marker genes Delta Varicose ( $\mathrm{Va}$ ) and Bare ( $\mathrm{Ba}$ ), which are both lethal in homozygous condition. The chromosome marked by $V a$ gene carries the $c u$ and $c h$ mutants and the $O_{3+4+\text { VIII+210 }}$ arrangement, while the chromosome with the $B a$ gene is $O_{\mathrm{ST}}$.

\section{Obtention of strains $\mathrm{O}_{\mathrm{ST}}$ and $\mathrm{O}_{3+4+7}$}

In order to obtain independently derived strains for the $O_{\mathrm{ST}}$ and $\mathrm{O}_{3+4+7}$ chromosome arrangements of $D$. subobscura, wild flies of this species were trapped in November, 1980, from a natural population located on the south slopes of El Pedroso mountain, $3 \mathrm{~km}$ from Santiago de Compostela (N.W. of Spain). A sample was taken in a pine forest (Pinus pinaster) by sweeping over conventional banana baits. The wild male flies were individually mated to $\mathrm{cu} c h / c u c h$ females and a single $F_{1}$ phenotypically wild male $(++/ c u c h)$ was backcrossed with $c u c h / c u c h$ females. The identification of the chromosomal arrangements in the wild $O$ chromosomes was performed in thirdinstar larvae obtained from the progeny of the backcrosses. The squash technique and staining with lactoacetic orcein (lactic acid:acetic orcein, $3: 1)$ has been used to observe the polytene chromosomes. Eight larvae of the progenies from backcrosses were analyzed by which the probability of not detecting the wild $O$ chromosome equals to $0 \cdot 004$. 
When the arrangement of each wild $O$ chromosome was established (no more than two backcrosses with the $c u$-ch strain were performed), the isogenisation of these chromosomes was initiated. Only chromosomes bearing the $\mathrm{O}_{\mathrm{ST}}$ or $\mathrm{O}_{3+4+7}$ arrangements were used. The $++/ c u c h$ males carrying a wild $O$ chromosome with either $O_{\mathrm{ST}}$ or $\mathrm{O}_{3+4+7}$ arrangements were crossed to $\mathrm{Va} / \mathrm{Ba}$ females and, according to the cross procedure shown in fig. 1 , homozygous wild $O$ chromosomes were obtained. In fig. 1 , the sex of the two genotypes of the third cross was dependent on the chromosome arrangement carried by the wild $O$ chromosome. The chromosome marked with $\mathrm{Va}$ carries the inversion complex $O_{3+4+\mathrm{VIII}+210}$ and so recombination can occur in the female $\mathrm{O}_{3+4+\mathrm{VIII}+210} / \mathrm{O}_{3+4+7}$ at the end of the chromosome in the region $O_{3+4}$ (Sperlich et al., 1977). Consequently, the isogenisation of $\mathrm{O}_{3+4+7}$ wild chromosomes was performed by using as the female parental the flies which were heterozygous for the $\mathrm{O}_{3+4+7}$ and the chromosome with the dominant marker $\mathrm{Ba}$ (which is $\mathrm{O}_{\mathrm{ST}}$ ), given that recombination is inhibited in the $O_{\mathrm{ST}} / \mathrm{O}_{3+4+7}$ karyotype (Krimbas and Zouros, 1969; Sperlich and Feuerbach-Mravlag, 1974; C. Zapata, unpublished results).

The isogenic strains $O_{\mathrm{ST}} / O_{\mathrm{ST}}$ and $\mathrm{O}_{3+4+7} / \mathrm{O}_{3+4+7}$ were assayed for the enzyme peptidase-1 (PEPT-1) by means of horizontal starch gel electrophoresis (Fontdevila et al., 1983). The Pept-1 locus is on the $O$ chromosome within the $\mathrm{O}_{3+4}$ arrangement (Loukas et al., 1979). We use the allozymes of the Pept-1 locus as genetic markers for the chromosomal arrangements given that, as stated above, recombination in the heterokaryotype $\mathrm{O}_{\mathrm{ST}} / \mathrm{O}_{3+4+7}$ is not possible. The Pept $-1^{1 \cdot 00}$ and Pept $-1^{0.40}$ alleles were used to mark the $\mathrm{O}_{\mathrm{ST}}$ and $\mathrm{O}_{3+4+7}$ chromosomal arrangements, respectively. This allows us to manipulate a high number of individuals with a reasonable effort. A total of 20 isogenic strains $O_{\mathrm{ST}}-P e p t-1^{1.00}$ and 20 isogenic strains $\mathrm{O}_{3+4+7}-$ Pept-1 ${ }^{0.40}$ were obtained. These isogenic strains were defined as having a normal chromosomal viability $(>0.50)$ with regard to the $V a / B a$ marker stock used in the cross procedure (fig. 1).

\section{Sexual selection experiment}

Two population cages $(30 \times 20 \times 10 \mathrm{~cm})$, each containing 15 cups of standard cornmeal-agar-yeast medium ( $20 \mathrm{cc}$ per cup) were established on September 16,1982 . One population was founded with the $20 O_{\mathrm{ST}^{-}}-$Pept- $^{1 \cdot 00}$ isogenic lines and the other

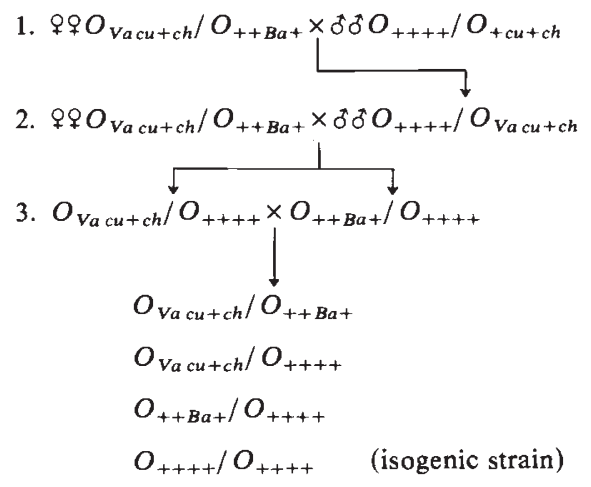

Figure 1 Cross procedure to obtain the isogenic strains for the chromosome $O$ of $D$. subobscura.

with the $20 \mathrm{O}_{3+4+7}-\mathrm{Pept}^{0.40}$. These populations, named stock populations, were maintained at $17^{\circ} \mathrm{C}, 70$ per cent relative humidity, until the start of the experiment 5 months later (under the present conditions, the generation time is approximately one month). Therefore, the wild $O$ chromosomes were freely allowed to recombine.

The experiments on mating behaviour of karyotypes for the chromosomal arrangements $O_{\mathrm{ST}}$ and $\mathrm{O}_{3+4+7}$ were conducted in large experimental populations (mating population cages of $30 \times 20 \times$ $10 \mathrm{~cm}$ ). The determination of the frequencies of matings between specific karyotypes is possible by diagnosing the karyotype of a single female and her offspring to infer which male mated with her. The determination of a female's mating partner is based on the assumption that the female is inseminated only once. Although $D$. subobscura females were believed to be completely monogamous (Maynard Smith, 1956), Loukas et al., (1981) have recently estimated the frequency of multi-inseminated females in nature as being 28 per cent. From laboratory experiments, these authors concluded that the time interval between two consecutive inseminations was not greater than 72 hours. Taking these results into account, preliminary experiments, where 400 pairs of flies (10 pairs per each isogenic line) were allowed to mate in population cages for different periods of time $(4,6,12$ and 24 hours), were carried out to determine whether or not the individual female had mated with two karyotypically different males by looking for segregation at the Pept-1 locus in her offspring. After mating the females recovered from the cages were $82,87,82$ and 87 per cent of the total of introduced females for the 4, 6, 12 and 24 hour periods, being the percentage of females which produced offspring $64,68,72$ and 75 per cent, respectively. Since no double-inseminated female 
was detected, the period of time of 24 hours was used in all experiments.

For the experiment on sexual selection three different karyotype frequencies $\left(30\right.$ per cent $O_{\mathrm{ST}}$ 50 per cent $O_{\mathrm{ST}}$ and 70 per cent $O_{\mathrm{ST}}$ ) were used. A total of six mating cages, two for each karyotypic frequency, were set up. The adult flies were introduced in Hardy-Weinberg proportions and the composition of the mating populations is shown in table 1 . The flies used in the experiment were obtained by collecting eggs for successive days on vials with fresh medium, placed at two different sites in the stock populations. Immediately after the collection, the eggs were transferred in numbers of $100-120$ to $250 \mathrm{cc}$ bottles containing $50 \mathrm{cc}$ of fresh culture medium, allowing them to hatch and develop. In order to obtain the heterokaryotypic flies $O_{\mathrm{ST}} / O_{3+4+7}$, equal number of males and females from each stock population, obtained by randomly sampling the adults hatched from previously collected eggs, were crossed and the females allowed to lay eggs which were transferred to $250 \mathrm{cc}$ bottles as above. Equal number of matings $\$ q O_{\mathrm{ST}} / \mathrm{O}_{\mathrm{ST}} \times \delta^{\top} \mathrm{O}_{3+4+7} / \mathrm{O}_{3+4+7}$ and qo $\mathrm{O}_{3+4+7} / \mathrm{O}_{3+4+7} \times \delta^{\circ} \mathrm{O}_{\mathrm{ST}} / \mathrm{O}_{\mathrm{ST}}$ were carried out. Males and females for the experiments were stored under near-optimal conditions before being added, unetherised, to the mating cages. These populations are named: $30-\mathrm{I}, 50-\mathrm{I}, 70-\mathrm{I}$ (the numbers refer to the frequency of $O_{\mathrm{ST}}$ ) the first three populations set up on February 18, 1983; and 30-II, 50-II, 70-II the three set up 2 months later (table 1). Each population cage was begun by placing 400 virgin females 5 to 7 days old. An equal number of same age males were then added (care was taken to avoid the potential bias due to differential male activity as a function of the position of the male in the storage vial (Markow 1980)) and the flies were allowed to mate for a period of 24 hours. The flies were then separated and the females were placed individually in vials $(2.5 \times 8 \mathrm{~cm}$, with $5 \mathrm{cc}$

Table 1 Composition of the population cages for the sexual selection experiment

\begin{tabular}{|c|c|c|c|c|}
\hline \multirow{2}{*}{$\begin{array}{l}\text { Mating } \\
\text { cage }\end{array}$} & \multicolumn{3}{|c|}{$\begin{array}{c}\text { Input individuals } \\
\text { (equal number of males and females) }\end{array}$} & \multirow[b]{2}{*}{${ }_{7}$ Total } \\
\hline & $O_{\mathrm{ST}} / O_{\mathrm{ST}}$ & $O_{\mathrm{ST}} / O_{3+4+7}$ & $O_{3+4+7} / O_{3+4+7}$ & \\
\hline $30-I$ & 72 & 336 & 392 & 800 \\
\hline $50-I$ & 200 & 400 & 200 & 800 \\
\hline $70-I$ & 392 & 336 & 72 & 800 \\
\hline 30-II & 72 & 336 & 392 & 800 \\
\hline 50-II & 200 & 400 & 200 & 800 \\
\hline 70-II & 392 & 336 & 72 & 800 \\
\hline
\end{tabular}

of food). These females were allowed to lay eggs for 8-10 days and then analysed for their Pept-1 locus. In order to know the female's mating partner, a total of 8 offspring of each homokaryotypic female were assayed for Pept-1. In case of a heterokaryotypic female the determination requires at least 18 offspring.

All the experiments were carried out at $17^{\circ} \mathrm{C}$, 70 per cent relative humidity, with continuous lighting.

\section{RESULTS}

The frequencies of each type of mating observed in the six population cages are given in table 3 (the data are shown in the form indicated in table 2 ). The average number ( \pm standard error) of recorded matings per cage is $321( \pm 3)$, which means that about the 80 per cent of the females introduced into the cages produced offspring from matings. Comparisons of the data from each pair of replicates at a particular frequency showed no significant heterogeneity. The analysis of data was made in terms of the three main components of mating behaviour: differential male mating success, differential female mating success and pattern of mating (Anderson and McGuire, 1978; Alvarez and Fontdevila, 1981; Majerus et al., 1982). The log likelihood ratio test, or G statistic (Sokal and Rohlf, 1981) was used, which allow a straightforward statistical test for the detailed analysis of mating behaviour. The results of the G-test are given in table 4 . The G-test for males measures the deviation of the mating frequencies of male karyotypes from the karyotypic frequencies in the population cages. In this way, we test for differential male mating success. Similarly, the G statistic for females tests the significance of female sexual selection. The third component (departure from random mating) tests for deviations from random mating in the $3 \times 3$ table of contingency. The value of the G-test for the total measures the deviations of the observed matings from the expectations based on the frequencies of the karyotypes, mated at random, in the experiments and is obviously affected by each of the three components of the mating behaviour.

In table 4 total $G$ statistic shows significant deviations of the observed matings from the expectations in populations $30-\mathrm{II}, 70-\mathrm{II}$ and 70 pooled. The analysis shows that this is mainly due to the differential male mating success, although some female sexual selection seems to occur in the populations where the frequency of $O_{\mathrm{ST}}$ is 70 per 
Table 2 Form of data obtainable from mating pairs

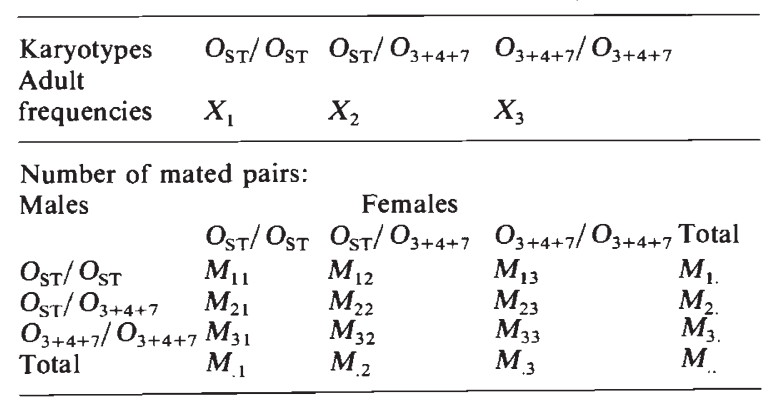

Table 3 Frequencies of mating pairs in the experimental populations arranged according to table 2

\begin{tabular}{|c|c|c|c|c|c|c|c|}
\hline \multirow{2}{*}{\multicolumn{4}{|c|}{$\begin{array}{l}\text { POPULATION 30-I } \\
\text { Mating pairs }\end{array}$}} & \multicolumn{4}{|c|}{ POPULATION 30-II } \\
\hline & & & & \multicolumn{4}{|c|}{ Mating pairs } \\
\hline 5 & 14 & 12 & 31 & 4 & 10 & 29 & 43 \\
\hline 12 & 55 & 66 & 133 & 13 & 48 & 78 & 139 \\
\hline 11 & 59 & 75 & 145 & 8 & 69 & 69 & 146 \\
\hline 28 & 128 & 153 & 309 & 25 & 127 & 176 & 328 \\
\hline \multirow{2}{*}{\multicolumn{4}{|c|}{$\begin{array}{l}\text { POPULATION 50-I } \\
\text { Mating pairs }\end{array}$}} & \multirow{2}{*}{\multicolumn{4}{|c|}{$\begin{array}{l}\text { POPULATION 50-II } \\
\text { Mating pairs }\end{array}$}} \\
\hline & & & & & & & \\
\hline 18 & 45 & 22 & 85 & 15 & 47 & 23 & 85 \\
\hline 30 & 84 & 45 & 159 & 39 & 79 & 56 & 174 \\
\hline 20 & 38 & 16 & 74 & 20 & 28 & 20 & 68 \\
\hline 68 & 167 & 83 & 318 & 74 & 154 & 99 & 327 \\
\hline \multirow{2}{*}{\multicolumn{4}{|c|}{$\begin{array}{l}\text { POPULATION 70-I } \\
\text { Mating pairs }\end{array}$}} & \multirow{2}{*}{\multicolumn{4}{|c|}{$\begin{array}{l}\text { POPULATION 70-II } \\
\text { Mating pairs }\end{array}$}} \\
\hline & & & & & & & \\
\hline 58 & 72 & 16 & 146 & 57 & 52 & 9 & 118 \\
\hline 71 & 61 & 11 & 143 & 68 & 74 & 24 & 166 \\
\hline 10 & 19 & 6 & 35 & 16 & 19 & 3 & 38 \\
\hline 139 & 152 & 33 & 324 & 141 & 145 & 36 & 322 \\
\hline
\end{tabular}

cent. It is worth saying that the value of 5.97 for the "deviation in males" component in the 30 pooled "population" is practically significant at the 5 per cent level (the critical value for 2 degrees of freedom is 5.99). Therefore, we can safely conclude that there is some indication of male sexual selection in the populations with a 30 per cent frequency of $O_{\mathrm{ST}}$, in addition to the clearly detected one at the frequency of 70 per cent $O_{\mathrm{ST}}$. In all cases but one (population 30-II), the analysis shows that there are no significant deviations from random mating. This is not an unusual result and several authors have reported cases where sexual selection is operating on a genetic system and random mating is not disturbed (Anderson and McGuire, 1978; O'Donald, 1980; Alvarez and Fontdevila, 1981).

The $G$ statistic tests for the existence of significant differences among karyotypes in mating success, but does not quantify these differences. The estimation of the relative adaptive values for sexual selection will allow us a proper knowledge of the pattern of selection operating on the different karyotypes. One point worth noting is that several indices currently used in the literature obscure more than clarify the significant aspects of the mating behaviour (Merrel, 1984), and others measure the same thing but are called differently: Petit's (1958) k coefficient and the male competitive index, CI (Latter and Robertson, 1962), used by Sharp (1982, 1984). Evidently, the more obvious form of measuring sexual selection is to express mating success in terms of fitness values. In this way, sexual selection is measured by means of indices with a true biological meaning. The differential mating success of male and female karyotypes can be properly estimated by measuring the effect of selection on the change in frequency of each of the two homokaryotypes $\left(O_{\mathrm{ST}} / O_{\mathrm{ST}}\right.$ and $\left.O_{3+4+7} / O_{3+4+7}\right)$, relative to the change in the heterokaryotype frequency, between the input and output karyotype distributions in the experimental populations (cross-product ratio estimators (Cook, 1971)). The fitness values for sexual selection are obtained from table 2 . These are:

$$
\begin{aligned}
W_{O_{\mathrm{ST}}}^{\delta} & =\left(M_{1} / M_{2}\right)\left(X_{2} / X_{1}\right) ; \\
W_{O_{3+4+7}}^{\delta} & =\left(M_{3} / M_{2}\right)\left(X_{2} / X_{3}\right)
\end{aligned}
$$

to estimate the differential male mating success,

Table 4 Analysis of the components of mating behaviour in three karyotypes of $D$. subobscura by means of G statistic

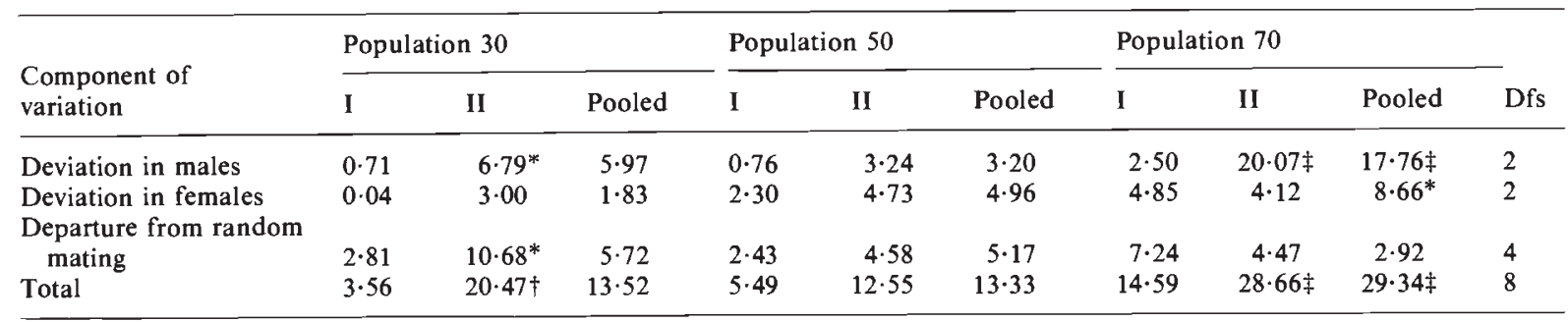

* Significant at the 0.05 level.

$\uparrow$ Significant at the 0.01 level.

$\ddagger$ Significant at the 0.001 level. 
and

$$
\begin{aligned}
W_{O_{\mathrm{ST}}}^{Q} & =\left(M_{.1} / M_{.2}\right)\left(X_{2} / X_{1}\right) ; \\
W_{O_{3+4+7}} & =\left(M_{.3} / M_{.2}\right)\left(X_{2} / X_{3}\right)
\end{aligned}
$$

to estimate the differential female matıing capacity.

Anxolabehere et al. (1982), and more recently Connolly and Gliddon (1984), have shown that this kind of estimators is biased, especially for low gene frequencies. However, in our case the karyotypic frequencies used are not extremes, and the number of matings recorded are high enough for the bias to be negligible. Connolly and Gliddon (1984) have stressed that of more concern than bias is the large variability of the fitness estimators, particularly with low gene frequencies and small sample sizes. In the experiments we have carried out the numbers of each karyotype on which selection can act are high enough to overcome the difficulties pointed out by Connolly and Gliddon (1984). In addition, our main interest for using the sexual fitness estimators is not to test the statistical significance of differential male or female mating success (which has been done by means of $G$ statistic), but to look at the pattern of sexual selection for the various karyotypic frequencies tested.

The estimates of mating success for both the male and female homokaryotypes, relative to that of the heterokaryotype which is taken as equal to 1 , are presented in table 5. Fig. 2 shows graphically the estimates of relative male fitness values given in table 5. The main features of the results are that replication experiments behave similarly and that a pattern of frequency-dependent selection favouring the rarer homokaryotypes is observed from the fitness estimates of male sexual selection. The regression equations of male sexual fitness estimates on gene arrangement frequencies are $Y=$ $1.66-1.30 X$ for $O_{\mathrm{ST}}$ and $Y=0.78+0.47 X$ for $\mathrm{O}_{3+4+7}$. The tests of significance of the regression coefficients show that we can reject the null hypothesis that there is no regression, or that $\beta=0$, for the $O_{\mathrm{ST}}$ arrangement $\left(F_{[1,1]}=507 \cdot 00 ; P<0.05\right)$, but not for the $O_{3+4+7}\left(F_{[1,1]}=0.89 ; 0.50<P<\right.$
$0.75)$. Thus, the pattern of frequency dependent selection is more remarkable for the $O_{\mathrm{ST}} / O_{\mathrm{ST}}$ homokaryotypic males than for the $\mathrm{O}_{3+4+7} / \mathrm{O}_{3+4+7}$. The mating success of $\mathrm{O}_{3+4+7} / \mathrm{O}_{3+4+7}$ males is approximately the same in the populations with intermediate and low frequencies of $O_{\mathrm{ST}}$. On the other hand, the effect of differential female mating success may be an important component, especially in the populations where the frequency of $O_{\mathrm{ST}}$ chromosomal arrangement is 70 per cent. In all cases but one the sexual fitness estimates for the $O_{\mathrm{ST}} / O_{\mathrm{ST}}$ female homokaryotype is lower than the corresponding ones for $\mathrm{O}_{\mathrm{ST}} / \mathrm{O}_{3+4+7}$ and $\mathrm{O}_{3+4+7} / \mathrm{O}_{3+4+7}$ karyotypes. It is also remarkable that no heterosis is observed for either male or female sexual selection at any of the frequencies tested. In all the populations the karyotype with a mating advantage is always one of the homokaryotypes.

\section{DISCUSSION}

Two main features arise from the results reported in this work: the pattern of mating of the three karyotypes of $D$. subobscura is at random and there is a frequency-dependent mating success in favour of minority males. Although the phenomenon of rare male mating advantage is not new, it had never been reported for $D$. subobscura karyotypes. It is also interesting to note that heterosis for male mating success is absent and the higher mating capacity is always presented by one of the homokaryotypes.

Bryant et al., (1980) have called into question the widespread acceptance of the minority mating advantage phenomenon by claiming that there are a number of possible factors that could induce rare male advantages as an experimental bias. In their paper, Bryant et al. (1980) showed that harming the flies by means of wing clipping induces minority male mating success. Given that wing clipping has been a widely used technique, the claims made by Bryant et al. (1980) are justified. In the present

Table 5 Fitness estimates for mating success in karyotypes for the chromosome $O$ of $D$. subobscura

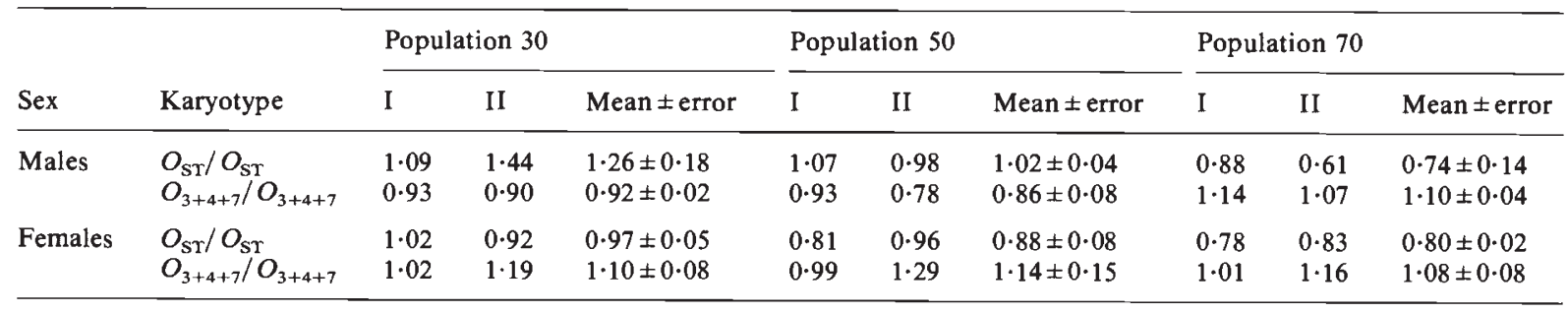




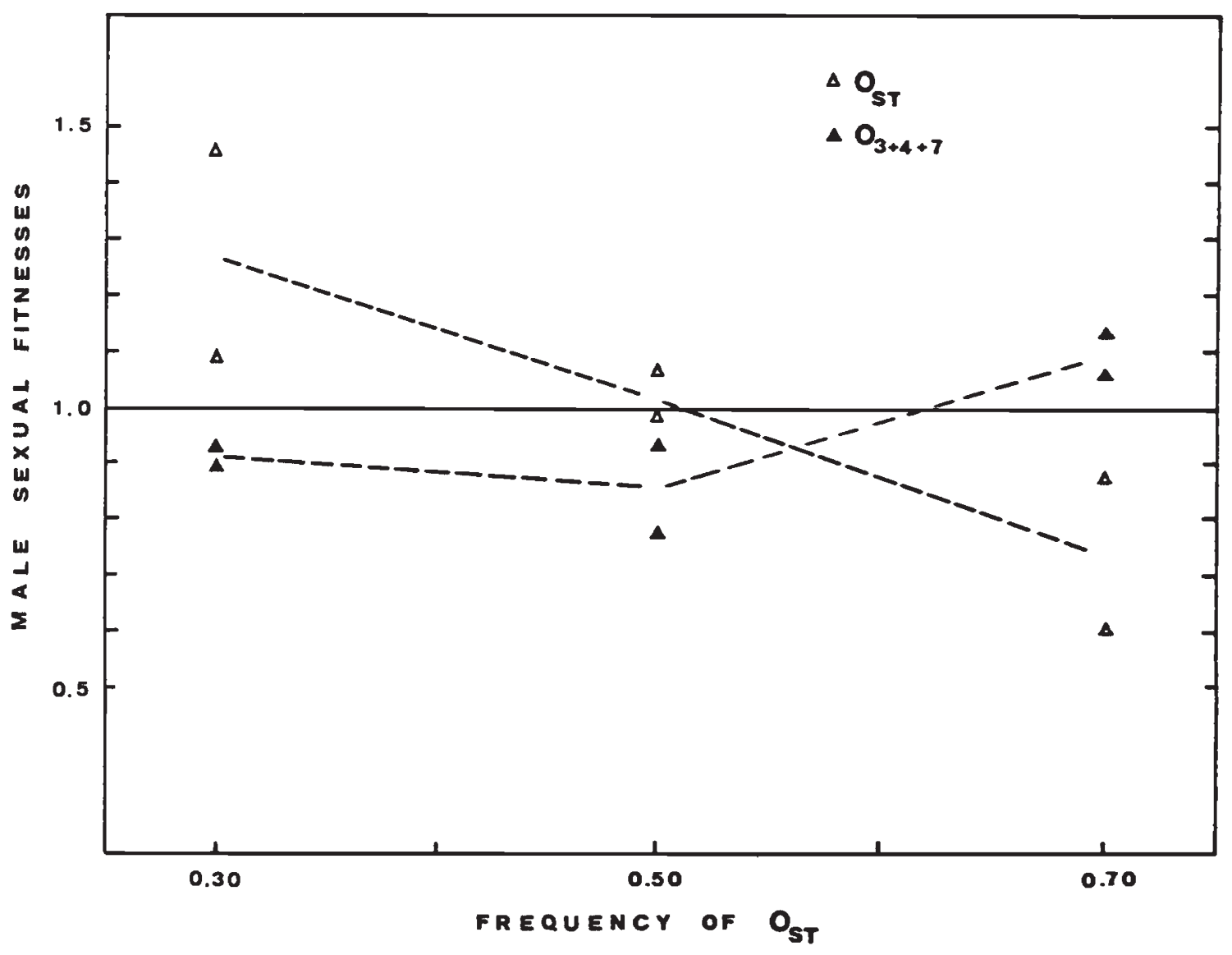

Figure 2 Relative fitness values for sexual selection of male karyotypes for the chromosome $O$ of $D$. subobscura.

work we have considered all the different sources of potential experimental bias in order to avoid them. On the one hand, the use of large mating population cages allow us to override sampling effects. As can be seen in table 1, the number of flies used for the experiments, in combination with the karyotype frequencies tested, ensures that selection can act on a reasonably large number of individuals of each karyotypic constitution. On the other hand, chromosomal arrangements were conveniently marked with peptidase-1 alleles and so competing flies were not damaged by marking.

With regard to the methods for estimating mating success, Alvarez et al. (1984) have shown that an erroneous definition of what sexual selection is can lead to the appearance of spurious patterns of frequency-dependent selection. In this sense, a proper differentiation between sexual selection, which involves frequency of mating, and pattern of mating, which is not a selective agent and concerns choice of mate, has been done in the analysis of mating behaviour. We can conclude that the rare male matings advantage reported in this work does occur in our experimental populations and is not a by-product of experimental manipulation or inappropriate fitness estimation.

Our experiments on mating behaviour were carried out to test for fitness differences among karotypes of $D$. subobscura and we did not design them to provide information about the underlying mechanisms by which rare male mating advantage can occur. However, it seems to us that some potentially important causes for the existence of differential mating success of karyotypes, which are not usually discussed in the literature on mating behaviour, deserve attention. Almost all explanations of the phenomenon of frequency-dependent mating success detected for Drosophila karyotypes competing in experimental populations take into account a purely behavioural basis. However, some possibility exist that fitness differences among competing karyotypes could be due to the unfavourable effects of recombination among loci linked within an inversion system if the chromosomes carried by 
those competing karyotypes differ in the average amount of recombination. This is due to the well established phenomenon that crossing over between well adapted homologous chromosomes yields chromosomes which on average reduce the fitness of their carriers. The important effects of this phenomenon were discussed by Wasserman (1968) and he showed that the recombinational load of chromosomal arrangements is frequencydependent. Charlesworth and Charlesworth (1975) have detected a substantial effect of recombination on female fecundity but a small and non-significant effect on egg-to-adult viability. These results indicate that the recombinational load can operate on the late components of overall fitness, which are characteristic of adult stages. In our experimental design, we have seriously taken into account the potentially important recombinational effect and we have tried to avoid differences in the average amount of recombination among the chromosomes carried by the experimental flies. As stated in Material and Methods, all the $O$ chromosomes of $D$. subobscura used in the sexual selection experiment were extracted from wild males and were not allowed to recombine until the foundation of the stock populations. The experimental flies we used in the establishment of the mating populations were derived from the homokaryotypic stock populations and their chromosomes do not differ in the average amount of recombination. On this ground, we feel the rare male mating advantage we have found for the homokaryotypes of $D$. subobscura could be likely explained on a behavioural basis. In this sense, we could think of models proposed by O'Donald (1980) and could assume that a constant proportion of females mate preferentially with one type of male and, given that no deviations from random mating were detected, the mating takes place without assortment. We could use the term "random preferential mating" to describe the process that was taking place in the mating populations (O'Donald, 1980 p. 21).

A stable equilibrium is attained in experimental population cages containing the $\mathrm{O}_{\mathrm{ST}}$ and $\mathrm{O}_{3+4+7}$ chromosomal arrangements of $D$. subobscura, as shown by Zapata et al. (1986). The equilibrium point is dependent upon the environmental conditions employed and ranges from 40 to 90 per cent for $O_{\mathrm{ST}}$. If the frequency-dependent male mating success we have detected were the only fitness component maintaining the chromosomal polymorphism in the experimental populations, we would predict from fig. 2 a stable equilibrium point somewhere around 50-60 per cent of $O_{\text {ST }}$. Although we have only assayed the mating struc- ture of $D$. subobscura for three karyotypic frequencies, it seems that sexual selection would not by itself explain the behaviour of the experimental populations, especially in those cages with the highest $O_{\mathrm{ST}}$ frequency. Other components of fitness such as viability and fecundity must be acting on this chromosomal polymorphism, at least in some environmental conditions. For the egg-toadult viability component, some unpublished results from our laboratory give the following relation of fitnesses among karyotypes: $O_{\mathrm{ST}} / \mathrm{O}_{\mathrm{ST}}>$ $O_{\mathrm{ST}} / O_{3+4+7}>O_{3+4+7} / O_{3+4+7}$. With this selection scheme the $\mathrm{O}_{3+4+7}$ gene arrangement would eventually be lost in the experimental populations, a result which has not been observed. The advantage of the $\mathrm{O}_{3+4+7} / \mathrm{O}_{3+4+7}$ males for mating success when they are at low frequency would contribute to overcome the inferiority of this karyotype in the egg-to-adult viability component. In this sense, the differential male mating success reported in the present study can be thought as a major component of fitness for $D$. subobscura karyotypes which decisively contributes to an overall balancing selection in the experimental populations.

Acknowledgements We are grateful to Alejandro Porto and Olga Castiñeiras for their invaluable technical assistance.

\section{REFERENCES}

ALVAREZ, G. AND FONTDEVilA, A. 1981. Selección sexual y apareamiento al azar en Drosophila melanogaster. Genét. Ibér.,33, 1-18.

AlvaREZ, G., SANTOS, M. AND ZAPATA, C. 1984. Frequencydependent selection arising from inappropriate fitness estimation. Evolution, 38, 696-699.

ANDERSON, w. w. 1969. Polymorphism resulting from the mating advantage of rare male genotypes. Proc. Natl. Acad. Sci. USA, 64, 190-197.

ANDERSON, W. W. AND BROWN, C. J. 1984. A test for rare male mating advantage with Drosophila pseudoobscura karyotypes. Genetics, 107, 577-589.

ANDERSON, W. W., LEVINE, L., OLVERA, O., POWELL, J. R., DE LA ROSA, M. E., SALCEDA, V. M., GASO, M. I. AND GUZMAN, J. 1979. Evidence for selection by male mating success in natural populations of Drosophila pseudoobscura. Proc. Natl. Acad. Sci. USA, 76, 1519-1523.

ANDERSON, W. W. AND MCGUIRE, P. R. 1978. Mating pattern and mating success of Drosophila pseudoobscura karyotypes in large experimental populations. Evolution, 32, $416-423$

ANDERSON, W. W. AND WATANABE, T. K. 1974. Selection by fertility in Drosophila pseudoobscura. Genetics, 77, 559-564.

ANXOLABEHERE, D., GOUX, J. M. AND PERIQUET, G. 1982. A bias in estimation of viabilities from competition experiments. Heredity, 48, 271-282.

BRITTNACHER, J. G 1981. Genetic variation and genetic load due to the male reproductive component of fitness in Drosophila. Genetics, 97, 719-730. 
BRYANT, E. H., KENCE, A. AND KIMBALL, K. T. 1980. A raremale advantage in the housefly induced by wing-clipping and some general considerations for Drosophila. Genetics, 96, 975-993.

BUNDGaARD, J. AND CHRISTIANSEN, F. B. 1972. Dynamics of polymorphisms. I. Selection components in an experimental population of Drosophila melanogaster. Genetics, $71,439-460$.

CHARLESWORTH, B. AND CHARLESWORTH, D. 1975. An experiment on recombination load in Drosophila melanogaster. Genet. Res. Camb., 25, 267-274.

CONNOLLY, J. AND GLIDDON, C. 1984. On the estimation of viabilities in competition experiments. Heredity, 53, 527543.

COOK, L. M. 1971. Coefficients of Natural Selection. Hutchinson Univ. Library, London.

DARWIN, C. R. 1871. The Descendent of Man, and Selection in Relation to Sex. John Murray, London.

DOBZHANSKY, TH. 1970. Genetics of the Evolutionary Process. Columbia Univ. Press, New York.

EHRMAN, L. AND PARSONS, P. A. 1976. The Genetics of Behaviour. Sinauer Associates Inc., Sunderland.

FONTDEVILA, A. AND MENDEZ, J. 1979. Frequency-dependent mating in a modified allozyme locus of Drosophila pseudoobscura. Evolution, 33, 634-640.

FONTDEVILA, A,, ZAPATA, C., ALVAREZ, G., SANCHEZ, L., MENDEZ, J. AND ENRIQUEZ, I. 1983. Genetic coadaptation in the chromosomal polymorphism of Drosophila subobscura. I. Seasonal changes of gametic disequilibrium in a natural population. Genetics, 105, 935-955

KOSKE, TH. AND MAYNARD SMITH, J. 1954. Genetics and cytology of Drosophila subobscura. X. The fifth linkage group. J. Genet., 52, 521-541.

KRIMBAS, C. B. AND LOUKAS, M. 1980. The inversion polymorphism of Drosophila subobscura. Evolutionary Biology, $12,163-234$.

KRIMBAS, C. B. AND ZOUROS, E. 1969. Crossing-over suppression between linked but non-overlapping inversions in D. subobscura. Dros. Inform. Serv., 44, 71-72.

LATTER, B. D. H. AND ROBERTSON, A. 1962. The effects of inbreeding and artificial selection on reproductive fitness. Genet. Res. Camb., 3, 110-139.

LOUKAS, M., KRIMBAS, C. B. AND VERGINI, Y. 1979. The genetics of Drosophila subobscura populations. IX. Studies on linkage disequilibrium in four natural populations. Genetics, 93, 497-523.

LOUKAS, M., VERGINI, Y. AND KRIMBAS, C. B. 1981. The genetics of Drosophila subobscura populations. XVIII. Multiple insemination and sperm displacement in Droscphila subobscura. Genetica, 57, 29-37.

MAJERUS, M., O'DONALD, P. AND WEIR, J. 1982. Evidence for preferential mating in Adalia bipunctata. Heredity, 49, $37-$ 49.

MARKow, T. A. 1980. Rare male advantage among Drosophila of the same laboratory strain. Behav. Genet., 10, 553-556.

MAYNARD SMITH, J. 1956. Fertility, mating behaviour and sexual selection in Drosophila subobscura. J. Genet., 54, 261-279.
MERREL, D. J. 1984. The analysis of mating behavior data Behav. Genet., 14, 153-156.

MONCLUS, M. AND PREVOSTI, A. 1971. The relationship between mating speed and wing length in Drosophila subobscura. Evolution, 25, 214-217.

O'DONALD, P. 1977. Theoretical aspects of sexual selection. Theor. Pop. Biol., 12, 298-334.

O'DONALD, P. 1980. Genetic Models of Sexual Selection. Cambridge Univ. Press, Cambridge.

PETIT, C. 1958. Le déterminisme génétique et psychophysiologique de la compétition sexuelle chez Drosophila melanogaster. Bull. Biol. France Belg., 92, 248-329.

PETIT, C. AND EHRMAN, L. 1969. Sexual selection in Drosophila. Evolutionary Biology, 3, 177-223.

PROUT, T. 1969. The estimation of fitnesses from population data. Genetics, 63, 949-957.

PROUT, T. 1971 $a$. The relation between fitness components and population prediction in Drosophila. I. The estimation of fitness components. Genetics, 68, 127-149.

PROUT, T. $1971 b$. The relation between fitness components and population prediction in Drosophila. II. Population prediction. Genetics, 68, 151-167.

SANTOS, M., Alvarez, G AND Zapata, C. 1984, La teoría de estimación de los valores adaptativos y el mantenimiento de la variabilidad genética de las poblaciones. Genét. Ibér. $36,165-185$.

SHARP, P. M. 1982. Competitive mating in Drosophila melanogaster. Genet. Res. Camb., 40, 201-205.

SHARP, P. M. 1984. The effect of inbreeding on competitive male-mating ability in Drosophila melanogaster. Genetics, $106,601-612$.

SOKAL, R. R. AND ROHLF, F. J. 1981. Biometry (2nd edition). W. H. Freeman, San Francisco.

SPERLICH, D. AND FEUERBACH-MRAVLAG, H. 1974. Epistatic gene interaction, crossing over, and linked and unlinked inversions in Drosophila subobscura. Evolution, 28, 67-75.

SPERLICH, D., FEUERBACH-MRAVLAG, H., LANGE, P., MICHAELIDIS, A. AND PENTZOS-DAPONTE, A. 1977. Genetic load and viability distribution in central and marginal populations of Drosophila subobscura. Genetics, 86, 835-848.

SPIESS, E. B. 1982. Do female flies choose their mates? Amer. Natur., 119, 675-693.

WASSERMAN, M. 1968. Recombination-induced chromosomal heterosis. Genetics, 58, 125-139.

WASSERMAN, M. 1972. Factors influencing fitness in chromosomal strains in Drosophila subobscura. Genetics, 72, 691708 .

YU, H. F. AND SPIESS, E. B. 1978. Chromosomal polymorphism and female receptivity in a natural population of Drosophila persimilis. Genetics, 90, 783-800.

ZAPATA, C., Alvarez, G., DOSil, M. AND FONTDEVILA, A. 1986. Genetic coadaptation in chromosomal polymorphism of Drosophila subobscura. II. Changes of gametic disequilibrium in experimental populations. Genetica (in press). 